\title{
Direct molecular diagnosis of CYP21 mutations in congenital adrenal hyperplasia
}

\author{
Hsien-Hsiung Lee, Hsiang-Tai Chao, Heung-Tat Ng, Kong-Bung Choo
}

\begin{abstract}
The majority of congenital adrenal hyperplasia (CAH) cases arise from mutations in the steroid 21-hydroxylase (CYP21) gene. Without reliance on HLA gene linkage analysis, we have developed primers for differential polymerase chain reaction (PCR) amplification of the CYP21 gene and the non-functional CYP21P gene. Using the amplification created restriction site (ACRS) approach for direct mutational detection, a secondary PCR was then performed using a panel of primers specific for each of the 11 known mutations associated with CAH. Subsequent restriction analysis allowed not only the detection but also the determination of the zygosity of the mutations analysed. Existing deletion of the CYP21 gene could also be detected. In the analysis of 20 independent chromosomes in $\mathbf{1 1}$ families of CAH patients in Taiwan, four CYP21 mutation types, besides deletion, were detected. Interestingly, in five different alleles, the CYP21P pseudogene contained some polymorphisms generally associated with the CYP21 gene. These results suggest gene conversion events that are occurring in both CYP21P and CYP21 genes. Our combined differential PCR-ACRS protocol is simple and direct and is applicable for prenatal diagnosis of CAH using chorionic villi or amniotic cells.

( $\mathcal{A}$ Med Genet 1996;33:371-375)
\end{abstract}

Key words: CYP21; mutational analysis; congenital adrenal hyperplasia.

Recombinant DNA

Laboratory,

Department of

Medical Research and

Education and Center

for Molecular

Medicine, Veterans

General Hospital,

Shih Pai, Taipei,

Taiwan 11217,

Republic of China

$\mathrm{H}-\mathrm{H}$ Lee

K-B Choo

Department of

Obstetrics and

Gynecology, Veterans

General Hospital,

Taipei, Taiwan 11217,

Republic of China

$\mathrm{H}-\mathrm{H}$ Lee

H-T Chao

$\mathrm{H}-\mathrm{T} \mathrm{Ng}$

Correspondence to:

Dr Lee.

Received 4 September 1995 Revised version accepted for

publication

7 December 1995 multiple mutations known to affect P450c21 enzymatic activities.

The gene coding for $\mathrm{P} 450 \mathrm{c} 21$ is designated CYP21. However, there exists a second du- plicated copy, CYP21P, which shares a $98 \%$ nucleotide sequence homology with CYP21 in the exon sequences. ${ }^{34}$ However, only the CYP21 gene is functional, whereas the CYP21P sequence is an inactive pseudogene resulting from the presence of an $8 \mathrm{bp}$ deletion in exon 3 , a thymidine insertion in exon 7 , and a $\mathrm{C}$ to $\mathrm{T}$ nonsense mutation in codon 319 of exon 8, all of which result in frameshift mutations. ${ }^{3-5}$ Both the CYP21P gene and the active CYP21 gene are located at the $3^{\prime}$ terminus of each of the two genes encoding the fourth component of complement, $\mathrm{C} 4 \mathrm{~A}$ and $\mathrm{C} 4 \mathrm{~B}$, in the HLA class III gene region on the short arm of chromosome $6 .^{67}$

Among the known CYP21 mutations analysed, about $15 \%$ are mutations involving deletion of the entire CYP21 gene. ${ }^{8}$ However, gene conversion from the pseudogene to the active gene is more frequent than gene deletion. ${ }^{9-12}$ Cases with a combination of gene conversion and deletion through mixing of the CYP21P and CYP21 genes have also been reported. ${ }^{10}$ The numerous known pseudogene mutations, which are commonly expressed as CYP21 gene defects by gene conversion, were described by New ${ }^{2}$ and Forrest et al. ${ }^{8}$ Clinically, it has been shown that the aberrant splicing in intron 2 at nucleotide (nt) 656, the $8 \mathrm{bp}$ frameshift deletion at codon 111-113, the thymidine insertion at codon 306 , the nonsense mutation at codon 318 , and the single base substitution at codon 356 result in a complete inactivation of P450c21 and are found in the severe classical form of salt wasting disease. ${ }^{21112}$ If untreated with steroid hormones, such patients would die within the first few weeks of birth. Genital ambiguities are also found in female patients. The single base changes in exon 1 at codon 30 , exon 3 at codon 105 , exon 7 at codon 281 , and exon 10 at codon 453 are associated with the milder non-classical form of $\mathrm{CAH}$ since the mutations result in only partial loss of the P450c21 enzyme activity. ${ }^{113}$ The simple virilising characteristics found in some $\mathrm{CAH}$ patients are associated with a mutation in exon 4 at codon 172, which abolishes P450c21 activity. ${ }^{1114}$

Sexual ambiguity in female $\mathrm{CAH}$ patients constitutes a severe psychological problem. If detected in utero, hormonal treatment can alleviate the severity of the symptoms. Thus, a simple and accurate prenatal diagnosis of CYP21 gene mutations is needed to prevent the birth of an affected child with the CAH phenotype. Diagnosis of CYP21 gene deletion has previously been done by way of linkage analysis with HLA typing using restriction fragment length polymorphisms (RFLP). ${ }^{5691516}$ 
Table 1 ACRS detection of mutations in the CYP21 genes

\begin{tabular}{|c|c|c|c|c|c|c|}
\hline \multirow[t]{2}{*}{ Designation } & \multirow[t]{2}{*}{ Primer pair } & \multirow[t]{2}{*}{ Mutational allele } & \multicolumn{2}{|c|}{ Restriction site } & \multicolumn{2}{|c|}{ Fragment size $(b p)$} \\
\hline & & & Natural & Created & Normal & Mutant \\
\hline A & $\mathrm{C} 1 \mathrm{~N} / \mathrm{C} 2$ & Ex $1, \operatorname{cdn} 30$ & - & Pst $\mathrm{I}$ & 195 & $164+31$ \\
\hline B1 & $\mathrm{C} 3 \mathrm{~B} / \mathrm{C} 4 \mathrm{~A}$ & Int 2, nt 656 & - & SacI & 115 & $85+30$ \\
\hline B2 & $\mathrm{C} 3 \mathrm{~B} / \mathrm{C} 4 \mathrm{~A}$ & Ex $3, \operatorname{cdn} 111-3$ & - & RsaI & 115 & $89+26$ \\
\hline $\mathrm{C}$ & $\mathrm{C} 5 / \mathrm{C} 6$ & Ex $4, \operatorname{cdn} 172$ & - & MseI & 148 & $118+30$ \\
\hline D & $\mathrm{C} 7 \mathrm{D} 1 / \mathrm{C} 8$ & Ex $6, \operatorname{cdn} 236$ & - & $M b o \mathrm{I}$ & $114+26$ & 140 \\
\hline $\mathrm{E}$ & $\mathrm{C} 7 \mathrm{E} / \mathrm{C} 8$ & Ex $6, \operatorname{cdn} 237$ & - & TaqI & 140 & $116+24$ \\
\hline$\vec{F}$ & $\mathrm{C} 7 \mathrm{C} 1 / \mathrm{C} 8$ & Ex $6, \operatorname{cdn} 239$ & - & MseI & 140 & $110+30$ \\
\hline G & $\mathrm{C} 9 / \mathrm{C} 10-1$ & Ex $7, \operatorname{cdn} 281$ & ApaLI & & $116+101$ & 213 \\
\hline $\mathrm{H}$ & $\mathrm{C} 9 \mathrm{~A} / \mathrm{C} 9 \mathrm{~B}$ & Ex $7, \operatorname{cdn} 306$ & - & MwoI & $123+34$ & 157 \\
\hline $\mathrm{J} 1$ & $\mathrm{C} 11 / \mathrm{C} 12$ & Ex $8, \operatorname{cdn} 318$ & PstI & - & $146+51$ & 197 \\
\hline $\mathrm{J} 2$ & $\mathrm{C} 11 / \mathrm{C} 12$ & Ex $8, \operatorname{cdn} 356$ & - & MscI & 197 & $167+30$ \\
\hline
\end{tabular}

However, the ratios of CYP21/CYP21P by restriction map analysis were difficult to interpret. ${ }^{17}$ Other more recently developed techniques for the CYP21 detection of point mutation include allele specific oligonucleotide (ASO) hybridisation, ${ }^{9121819}$ specific primer amplification for direct sequencing, ${ }^{20-22}$ and PCR based single strand conformation polymorphism. ${ }^{23}$ However, in these protocols, contamination from the highly homologous pseudogene sequence is a major impediment. In particular, there is almost complete sequence homology between the two allelic CYP21 genes from exons 4 to $10,^{3-5}$ which makes it almost impossible to develop an accurate and reliable molecular diagnostic protocol for analysing the mutations in these exons precisely.

To circumvent the above problems and as a step towards prenatal diagnosis of $\mathrm{CAH}$, we describe here a PCR based approach which permits differential amplification of the CYP21P and CYP21 genes, followed by direct probing for the presence of known mutation sites in a secondary PCR analysis, using the well characterised amplification created restriction site (ACRS) approach. ${ }^{24}$ This approach has been used successfully for the detection of known mutations in a number of congenital diseases such as $\beta$ thalassaemia and phenylketonurea and in oncogenes such as ras. ${ }^{24-26}$

\section{Materials and methods SAMPLES}

Blood samples from normal healthy subjects and suspected $\mathrm{CAH}$ patients and available family members evaluated at the Obs/Gyn clinic of the Veterans General Hospital, Taipei were obtained. Amniotic fluid was also obtained in one case and was cultured before DNA extraction.

\section{DNA PURIFICATION}

Fresh blood samples or cultured cells were used for DNA preparation. Normally, a $3 \mathrm{ml}$ fresh blood sample was taken in a $15 \mathrm{ml}$ clean, disposable tube coated with EDTA and lysed with $9 \mathrm{ml}$ RBC buffer $\left(0.15 \mathrm{~mol} / 1 \mathrm{NH}_{4} \mathrm{Cl}\right.$, $0.1 \mathrm{mmol} / 1 \mathrm{EDTA}, 10 \mathrm{mmol} / 1 \mathrm{KHCO}_{3}, \mathrm{pH}$ $7 \cdot 3)$. After a 10 minute incubation at room temperature, the mixture was spun at $2000 \times g$ for 10 minutes. The supernatant was discarded leaving enough volume for resuspension. Three $\mathrm{ml}$ cell lysis buffer $(200 \mathrm{mmol} / \mathrm{l}$ Tris- $\mathrm{HCl}, \mathrm{pH}$ $8 \cdot 5,100 \mathrm{mmol} / 1 \mathrm{EDTA}, 35 \mathrm{mmol} / 1 \mathrm{SDS}$ ) was added to the mixture and mixed gently several times until a homogeneous phase was obtained. The homogeneous solution was added to $1 \mathrm{ml}$ of protein precipitation solution $(10 \mathrm{~mol} / \mathrm{l}$ $\mathrm{NH}_{4} \mathrm{Ac}$ ), and shaken or vortexed vigorously for 20 seconds to achieve uniformity. The mixture was centrifuged at $2000 \times g$ for 15 minutes and the supernatant was transferred to a clean tube for DNA precipitation by adding eight-tenth volume of isopropanol.

POLYMERASE CHAIN REACTION

To $2.5 \mu \mathrm{l}$ of genomic DNA ( $300 \mathrm{ng}$ ), $5 \mu \mathrm{l}$ of $10 \times$ PCR buffer and 0.75 units of Taq DNA polymerase (Expand Long Template PCR System, Boehringer Mannheim, FDR) were added. Primers (10 pmol each), dNTPs $(350 \mu \mathrm{mol} / 1 \mathrm{each})$, and sterile distilled water were added to the PCR mixture to make up a final reaction volume of $50 \mu \mathrm{l}$.

For primary PCR differential amplification of the CYP21A or CYP21B gene, the following PCR conditions were used: initial template denaturation at $94^{\circ} \mathrm{C}$ for four minutes, followed by 10 cycles at $94^{\circ} \mathrm{C}$ for 30 seconds, $59^{\circ} \mathrm{C}$ for 30 seconds, and $68^{\circ} \mathrm{C}$ for five minutes, and another 15 cycles at $94^{\circ} \mathrm{C}$ for 30 seconds and $68^{\circ} \mathrm{C}$ for five minutes. The secondary ACRS PCR mixture contained $0.5 \mu \mathrm{l}$ of the primary PCR product, $5 \mu \mathrm{l}$ of $10 \times$ PCR buffer $(100 \mathrm{mmol} / 1$ Tris- $\mathrm{HCl}, \mathrm{pH} 8.8,500 \mathrm{mmol} / \mathrm{l}$ $\mathrm{KCl}, 25 \mathrm{mmol} / \mathrm{l} \mathrm{MgCl}_{2}, 0 \cdot 1 \%$ Tween 20 ), $5 \mu \mathrm{l}$ of $25 \mathrm{mmol} / 1 \mathrm{MgCl}_{2}, 0.08$ units of Thermoprime plus DNA polymerase (Advanced Biotechnologies Ltd, UK), $7.5 \mathrm{pmol}$ of each primer, and $75 \mu \mathrm{mol} / 1$ of each of the dNTPs in a final volume of $50 \mu \mathrm{l}$. PCR was performed for 25 cycles at $94^{\circ} \mathrm{C}$ for 30 seconds, $59^{\circ} \mathrm{C}$ for 30 seconds, and $72^{\circ} \mathrm{C}$ for 30 seconds.

\section{RESTRICTION ENZYME REACTION}

Following the secondary ACRS PCR, $5 \mu \mathrm{l}$ of the PCR product was incubated for at least two hours with 5 to 10 units of a specific restriction enzyme (table 1), then analysed by electrophoresis in a $2.5 \%$ Metaphor (FMC Bioproducts USA).

\section{Results and discussion}

To distinguish between the CYP21P and CYP21 genes, two pairs of oligonucleotide primers (table 2A) were designed for differential amplification of these genes. The sequence of the forward primers (21AF and $21 \mathrm{BF}$, table $2 \mathrm{~A}$ ) was derived from a site about $100 \mathrm{bp}$ upstream from the TATA box of the CYP21 genes and the sequence of the reverse primers (21AR and 21BR, table 2A) mapped in a region $20 \mathrm{bp}$ preceding the polyadenylation signal. The forward or the reverse primer sequences of the two gene sequences differed by at least three nucleotides including the nucleotide located at the $3^{\prime}$ end of the oligonucleotides to increase sequence differentiation during the amplification step.

On primary $P C R$ amplification using primers 21AF/AR and 21BF/BR of the CYP21P and 
Table 2 Primers for PCR amplification and ACRS mutational analysis of the CYP21 genes

\begin{tabular}{lll}
\hline Primer & Sequence $\left(5^{\prime} \rightarrow 3^{\prime}\right)$ & Position \\
\hline (A) Amplification of the CYP21 genes (primary PCR) & \\
21AF & GGGTCGGTGGGAAGGCACCTGAG & nt -103 to -125 \\
21AR & GATTAAGCCTCAATCCTCTGCGGCA & nt 3185 to 3161 \\
21BF & TCGGTGGGAGGGTACCTGAAG & nt -102 to -122 \\
21BR & AATTAAGCCTCAATCCTCTGCAGCG & nt 3177 to 3153 \\
(B) Amplification for ACRS analysis of specific regions (secondary PCR)* & \\
C1N & CTACACAGCAGGAGGGATGGC & nt -53 to -63 \\
C2 & AGCAAGTGCAAGAGGCCGGGGCAAGctG & nt 122 to 94 \\
C3B & TTCATCAGTTCCACCCTCCAGCCCCGA & nt 631 to 658 \\
C4A & CTTCTTGTGGGCTTTCCAGAGCAGGA & nt 743 to 719 \\
C5 & GAGGATTCTCTCTCCTCACCTGCAGCATtA & nt 970 to 1003 \\
C6 & TTGTCGTCCTGCCAGAAAAGGA & nt 1131 to 1110 \\
C7C1 & ATAGAGAAGAGGGATCACATCGGGGtA & nt 1366 to 1393 \\
C7D1 & AAGCAGGCCATAGAGAAGAGGGtTCAgA & nt 1357 to 1384 \\
C7E & AGCAGGCCATAGAGAAGAGGGATCACATC & nt 1358 to 1386 \\
C8 & TGCAAAAGAACCCGCCTCATAG & nt 1501 to 1480 \\
C9 & TGCAGGAGAGCCTCGTGGCAGG & nt 1578 to 1599 \\
C9A & CACAGCAAACACCCTCTCCTGGGCCGTGCT & nt 1732 to 1761 \\
C9B & AGCCCCAGCCGCACAGTGCTC & nt 1878 to 1858 \\
C10-1 & ACGCACCTCAGGGTGGTGAAG & nt 1789 to 1768 \\
C11 & GCTGGGGCAGGACTCCACCCGA & nt 1951 to 1973 \\
C12 & GTGCGGTGGGGCAAGGCTAAGGGCACAACtG & nt 2147 to 2117 \\
\hline
\end{tabular}

* Lower case letters indicate modified nucleotides.

CYP21 genes respectively, a $3.3 \mathrm{~kb}$ product was derived (fig $1 \mathrm{~A}$, lanes 1 and 3 ). The PCR products generated from CYP21P and CYP21 were distinguishable by digestion with $E c o$ RI. $E c o$ RI digestion of the CYP21P derived PCR product produced three fragments $(0.5,0.6$, and $2 \cdot 2 \mathrm{~kb}$ ) (fig $1 \mathrm{~A}$, lane 2 ) whereas digestion of the active CYP21 gene produced only two fragments $(1 \cdot 0$ and $2 \cdot 2 \mathrm{~kb}$ ) (fig $1 \mathrm{~A}$, lane 4 ). Thus, for a direct analysis of mutations in the CYP21 gene in an actual clinical situation, the combined use of CYP21 specific primers and analysis with $E c o$ RI would ensure that only the active gene sequence had been amplified and analysed.

In order to detect the various characterised CAH mutations (see text), the CYP21 primary PCR products were then used as templates in a secondary PCR. In this step, the amplification created restriction site (ACRS) approach was used. ${ }^{24}$ Region specific primers for 11 known mutation loci (tables 1 and $2 \mathrm{~B}$ ) were designed that would lead to the creation of new restriction recognition sites at these known mutation sites on secondary amplification (table 1).
In two cases (primer designations $\mathrm{G}$ and $\mathrm{J} 1$, table 1), the mutations had naturally created recognition sites for direct restriction detection. To establish the validity of this approach and to test all the ACRS primers designed, the 11 mutations being characterised in this study (table 1) were first examined in the CYP21P gene sequence, since all these mutations had been shown to occur in CYP21P. ${ }^{3-5}$ The ACRS PCR primer sequences are listed in table $2 \mathrm{~B}$ and the restriction enzymes that were required for the analysis of the ACRS PCR products and the expected enzyme digestion fragments are listed in table 1 . Note that in two cases using primer pairs $\mathrm{C} 3 \mathrm{~B} / \mathrm{C} 4 \mathrm{~A}$ and $\mathrm{C} 11 / \mathrm{C} 12$, the same PCR products were used for the analysis of different mutated sites by the use of different restriction enzymes. For simplicity, each PCR/restriction enzyme combination was assigned a designation (table 1).

After the primary differential amplification of the CYP21P and CYP21 genes from a leucocyte DNA preparation derived from a healthy male (fig 1A), the primary PCR products were subjected to the secondary ACRS PCR. Both CYP21P and CYP21 genes generated PCR products of identical size (fig 1B). The ACRS PCR products were then digested with appropriate restriction enzymes and the restriction patterns were compared (fig 2). In the CYP21P gene, homozygous mutated alleles were detected in most cases. Unexpectedly, on analysis of a number of healthy subjects, five of the loci were found to show the heterozygous state of wild type and mutated alleles. Five of these are found in the example shown in fig 2A (lanes 2, 4, 5, 17, and 20). In the ACRS analysis of the CYP21 gene of normal subjects, only normal alleles were detected in all 11 mutation sites (fig 2B).

The ACRS primers were further used in the analysis of 31 patients clinically suspected of having $\mathrm{CAH}$ and family members from 11 families, all of whom were ethnic Chinese Taiwanese. In these families, 20 independent chromosomes were available for analysis. Four of the $11 \mathrm{CAH}$ mutations analysed in this study
A
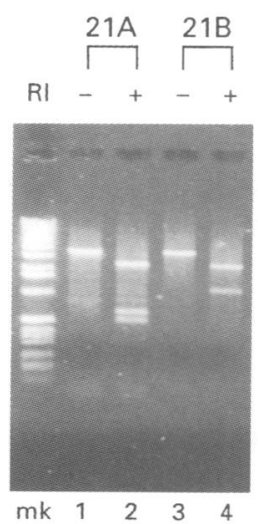

B

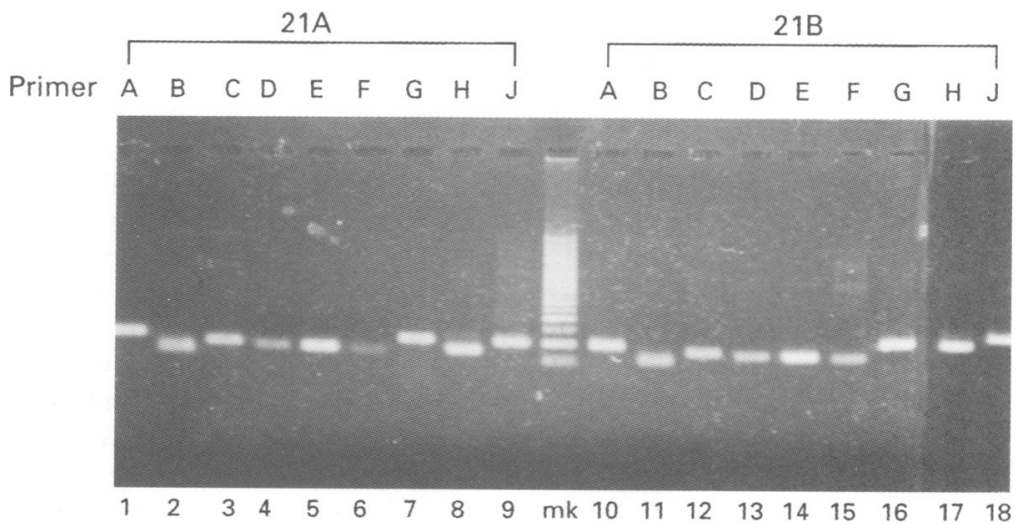

Figure 1 (A) Differential PCR amplification of the CYP21 genes. The CYP21P (21A) and CYP21 (21B) genes were amplified using the $21 A F / 21 A R$ and $21 B F / 21 B R$ primer pairs, respectively. The PCR products were analysed by digestion (+), or without digestion (-), with EcoRI (RI) restriction enzyme. $A 1$ kb ladder was used as a molecular marker in lane " $m k$ ". (B) ACRS amplification of the sequences containing the 11 mutation sites analysed in this study in both the CYP21P and CYP21 genes. The primer pairs used were those designated in tables 1 and $2 . A 100 b p$ ladder was used as a molecular marker in lane " $m k$ ". 

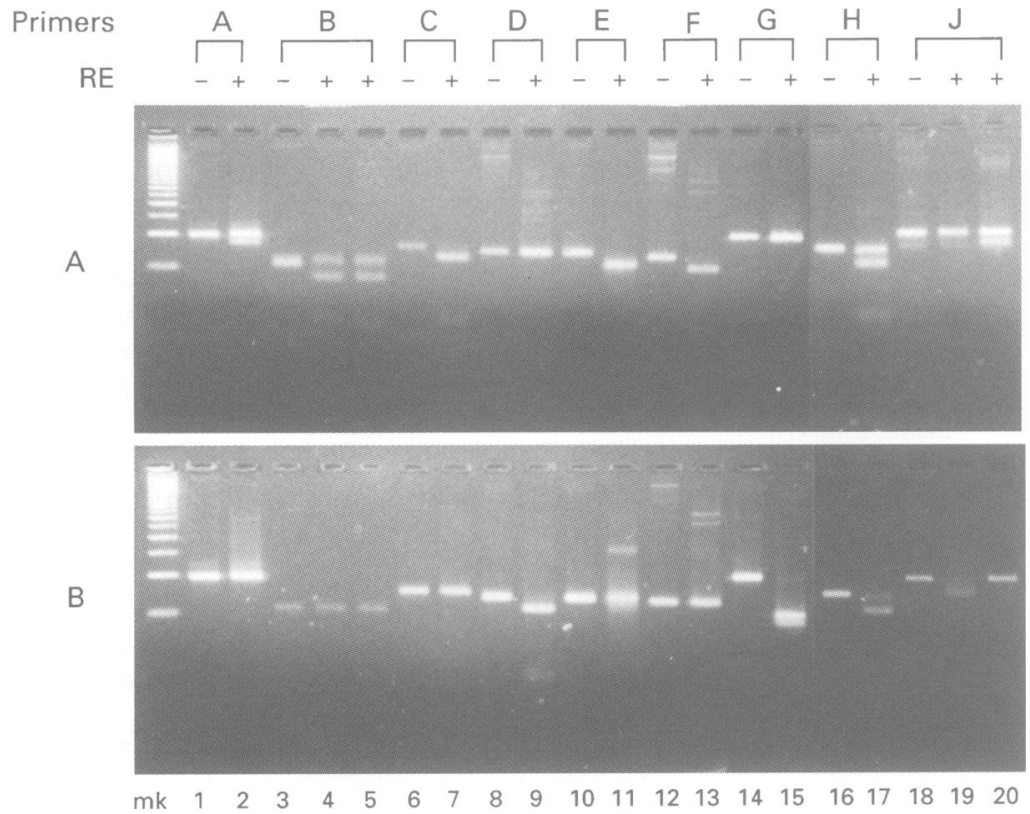

Figure 2 Restriction analysis of the ACRS amplification products of the CYP21P $(A)$ and CYP21 (B) genes. The primer pairs were those designated in table 1. Each ACRS amplification product was either untreated ("- "lanes) or treated ("+ "lanes) with an appropriate restriction enzyme (RE) (table 1). The marker used was a 100 bp ladder in lane " $m k$ ".

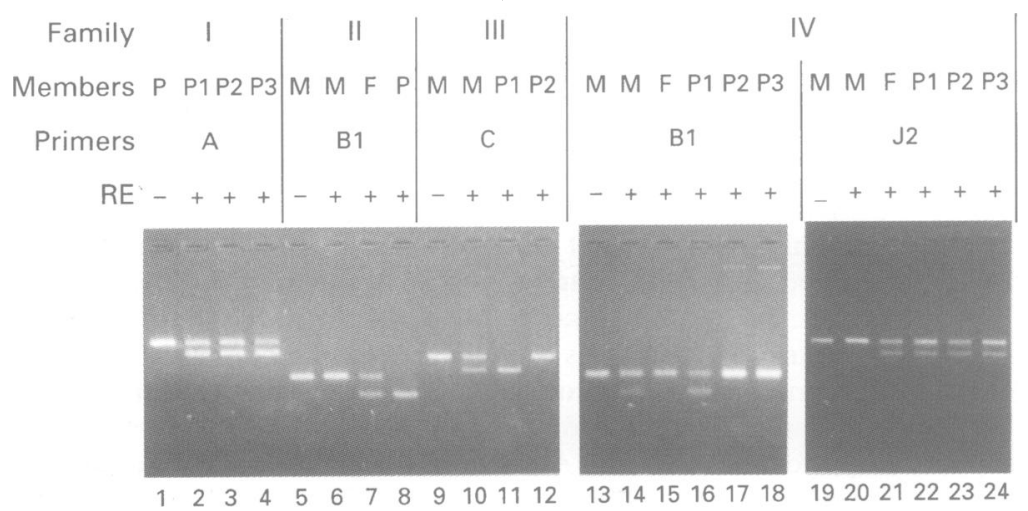

Figure 3 Analysis of the CYP21 gene in four different CAH families (I-IV). The members of the families available for the study are shown. "P" indicates proband, " $M$ " indicates mother, and " $F$ " indicates father. In families III and IV, more than one proband was analysed. The proband " $P 3$ " in family IV was a case of prenatal diagnosis using amniotic cells (see text). The primers and the restriction enzymes (RE) used, which led to the detection of the mutations, are listed in table 1.

were detected in these families (fig 3). Only one of the 11 families (family I) analysed showed the mutation at codon 30 of exon 1, which was associated with a potentially non-classical disorder. ${ }^{113}$ In family I (fig 3, lanes $1-4$ ), the two female probands (P1 and P2) (lanes 2 and 3 ) and the male proband (P3, lane 4) all carried the heterozygous alleles. However, the clinical manifestations of the two female probands were clitoromegaly and oligomenorrhoea. We speculate that this family probably carried an additional and uncharacterised mutation which had led to the clinical symptoms observed.

The mutation at nucleotide 656 of intron 2 , a premature splicing error, was detected in families II and IV. In family II (fig 3, lanes 5-8), the mother showed only the normal ACRS band (lane 6) but the father showed both the normal and the mutated ACRS bands (lane 7), indicating heterozygosity. However, the only male proband clearly showed the mut- ated ACRS band only (lane 8). The data indicate that the mother probably carried an intact copy of the CYP21 gene on one chromosome and a complete deletion of the CYP21 gene on the chromosome which was inherited by the proband. The probands had also inherited the mutated CYP21 allele from the father to give rise to the observed ACRS banding pattern. Clinically, both parents of family II were normal but the proband showed a picture of classical salt wasting type after birth.

The mutation at codon 172 in exon 4, a missense mutation, was detected in family III (fig 3, lanes 9-12), in which the mother showed both the normal and the mutated ACRS bands (lane 10), indicating heterozygosity. Although proband 2 (P2, female) of this family showed only the normal ACRS band (lane 12), her sister (proband 1, P1) (lane 11) carried only the mutated ACRS band. Since DNA from the father of this family was not available for analysis, we could only speculate that the father was also a heterozygous carrier of a CYP2 1 mutation at codon 172 of exon 4 . Alternatively, the father could have been a case of a deletion of the entire CYP21 gene in one of the chromosomes to have given birth to proband 1 . Clinically, proband 1 showed muscularity, clitoromegaly, and amenorrhoea, consistent with the molecular diagnosis. Proband 2 was clinically normal. It could not be determined here if proband 2 had inherited two normal alleles from both parents, or if she was a carrier of a chromosome with a missing CYP21 gene from the father.

Besides the mutation at nucleotide 656 of intron 2 as described above (fig 3, lanes 13-18), the mutation at codon 356 in exon 8 was also detected in family IV (fig 3, lanes 19-24). In this family, the mother showed both the normal and the mutated ACRS bands at nucleotide 656 of intron 2 (lane 14) indicating heterozygosity, whereas the father (lane 15) showed only the normal ACRS band at this mutation site. However, a normal ACRS band was observed at codon 356 of exon 8 in the mother (lane 20) whereas the father (lane 21) showed both the normal and the mutated ACRS bands indicating heterozygosity at this mutation site. Two living female probands (P1 and P2) and a case of prenatal diagnosis (P3) using cultured amniotic cells taken at the 15 th week of gestation were analysed. The fetus (P3) was determined to be male by analysis of the amelogenin gene. ${ }^{27}$ The female proband P1 clearly showed a normal and a mutated ACRS band in both the intron 2 and the exon 8 mutation sites (lanes 16 and 22), indicating double mutations. The other two probands, P2 and P3, showed only normal ACRS bands at the intron 2 mutation site (lanes 17 and 18), but showed both the normal and the mutated ACRS bands in exon 8 (lanes 23 and 24), indicating heterozygosity. Taken together, the data indicate that the mother carried a chromosome with a mutated intron 2 whereas the father carried a chromosome with a mutation in exon 8. Proband P1 appeared to have inherited both the mutated alleles from her parents. Clinically, P1 showed clitoromegaly and salt loss 
Table 3 CYP21 mutations detected in CAH patients in Taiwan

\begin{tabular}{llc}
\hline Mutational allele & Types of CAH & $\begin{array}{l}\text { No of independent } \\
\text { chromosomes }\end{array}$ \\
\hline Ex 1, cdn 30 & Non-classical & 1 \\
Int 2, nt 656 & Classical & 5 \\
Ex 4, cdn 172 & Simple virilisation & 6 \\
Ex 8, cdn 356 & Classical & 2 \\
Deletion & & 6 \\
Total & & 20 \\
\hline
\end{tabular}

after birth and was thus a classical form of $\mathrm{CAH}$. Although the parents and proband P2 were heterozygous carriers of these mutations in either intron 2 or exon 8, they were clinically normal. We could now predict that P3 should also be clinically normal at birth since he was a heterozygous carrier like his father.

In the analysis of 31 subjects in 11 different families, only four CYP21 mutations were detected in the Taiwanese CAH patients residing in Taiwan. The mutations at codon 30 in exon 1 and codon 356 in exon 8 were detected once and twice, respectively, in the 20 parental chromosomes analysed, whereas the intron 2 mutation and the exon 4 , codon 172 mutation were found in five and six parental chromosomes, respectively (table 3 ). A total of six of the 20 cases analysed $(30 \%)$ were suspected deletions of the entire CYP21 gene. Surprisingly, the coexistence of both mutated and normal alleles in the analysis of the CYP21P gene was seen in five loci including codon 30 in exon 1, nt 656 in intron 2, the 8 bp deletion in exon 3, codon 306 in exon 7, and codon 356 in exon 8 (fig $2 \mathrm{~A}$, lanes $2,4,5,17$, and 20 , respectively). Whether normal alleles also exist in other mutated loci at a lower frequency will need to be established. Furthermore, the relationship between mutations in the CYP21 gene in clinical $\mathrm{CAH}$ cases and the allelic type in the CYP21P gene in the same person also needs to be elucidated. Any gene conversion model to explain the occurrence of CYP21 mutations would have to take into consideration this observation.

As indicated above, by way of differential amplification of the CYP2 1 and the CYP21P genes, our method allows precise detection of multiple CYP21 mutations as well as deletions in family analysis without the need for HLA typing. Since no radiolabelling is involved, the protocol is suitable for clinical laboratories. Most importantly, the requirement of only a very small amount of materials for PCR makes the method applicable to prenatal diagnosis of $\mathrm{CAH}$ using amniotic cells or chorionic villi.

This work was supported in part by grant NSC85-2331-B-075051 from the National Science Council of the Republic of China, and in part by grant 182 from the Veterans General Hospital, Taipei, Taiwan.

1 New MI, Levine LS. Recent advances in 21-hydroxylase deficiency. Annu Rev Med 1984;35:649-63.
2 New MI. 21-hydroxylase deficiency congenital adrenal hyperplasia. F Steroid Biochem Molec Biol 1994;48:15-22.

3 Higashi Y, Yoshioka H, Yamane $M$, et al. Complete nucleotide sequence of two steroid 21-hydroxylase genes tandemly arranged in human chromosome: a pseudogene demly arranged in human chromosome: a pseudogene and a gen

4 White PC, New MI, Dupont B. Structure of human steroid 21-hydroxylase genes. Proc Natl Acad Sci USA 1986;83: 5111-15

5 Rodrigues NR, Dunham I, Yu CY, et al. Molecular characterization of the HLA-linked steroid 21-hydroxylase B gene from an individual with congenital adrenal hyperplasia. EMBO f 1987;6:1653-61.

6 White PC, New MI, Dupont B. HLA-linked congenital adrenal hyperplasia results from a defective gene encoding a cytochrome P-450 specific for steroid 21-hydroxylation. Proc Natl Acad Sci USA 1984;81:7505-9.

7 Carroll MC, Palsdottir A, Belt KT, Porter RR. Deletion of complement $\mathrm{C} 4$ and steroid 21 -hydroxylase genes in the HLA class III region. EMBO f 1985;4:2547-52.

8 Forrest MG, David M, Morel Y. Prenatal diagnosis and orrest MG, David M, Morel Y. Prenatal diagnosis and
treatment of 21 -hydroxylase deficiency. $\mathcal{F}$ Steroid Biochem treatment of 21-hydroxyla

9 Higashi Y, Tanae A, Inoue H, Fujii-Kuriyama Y. Evidence for frequent gene conversion in the steroid 21 -hydroxylase P-450 (C21) gene: implications for steroid 21-hydroxylase deficiency. Am f Hum Genet 1988;42:17-25.

0 Miller WL, Levine LS. Molecular and clinical advances in congenital adrenal hyperplasia. $\mathcal{F}$ Pediatr 1987;111:1-17.

1 Higashi Y, Hiromasa T, Tanae A, et al. Effects of individual mutations in the P-450 (C21) pseudogene on the P450 (C21) activity and their distribution in the patient genomes of congenital steroid 21-hydroxylase deficiency. F Biochem 1991;109:638-44.

12 Mornet E, Cre'te' P, Kuttenn F, et al. Distribution of deletions and seven point mutations on CYP21B genes in three clinical forms of steroid 21-hydroxylase deficiency. Am f Hum Genet 1991;48:79-88.

13 Tusie-Luna MT, Speiser PW, Dumic M, New MI, White PC. A mutation (Pro-30 to Leu) in CYP21 represents a potential nonclassic steroid 21-hydroxylase deficiency allele. Mol Endocrinol 1991;5:685-92.

14 Chiou SH, Hu MC, Chung BC. A missense mutation at Ile $^{172} \rightarrow$ Asn or Arg $356 \rightarrow$ Trp causes steroid 21-hydroxylase deficiency. F Biol Chem 1990;265:3549-52.

15 Carroll MC, Campbell RD, Porter RR. Mapping of steroid 21-hydroxylase genes adjacent to complement component C4 genes in HLA, the major histocompatibility complex in man. Proc Natl Acad Sci USA 1985;82:521-5.

16 Matteson KJ, Phillips JA III, Miller WL, et al. P450XXI (steroid 21-hydroxylase) gene deletions are not found in family studies of congenital adrenal hyperplasia. Proc Natl family studies of congenital adrenal

17 Miller WL. Gene conversions, deletions and polymorphisms in congenital adrenal hyperplasia. Am f Hum Genet 1988; 42:4-7.

18 Owerbach D, Draznin MB, Carpenter RJ, Greenberg F. Prenatal diagnosis of 21-hydroxylase deficiency congenital adrenal hyperplasia using the polymerase chain reaction. Hum Genet 1992;89:109-10.

19 Speiser PW, Dupont J, Zhu D, et al. Disease expression and molecular genotype in congenital adrenal hyperplasia due to 21-hydroxylase deficiency. $\mathcal{F}$ Clin Invest 1992;90:58495

20 Owerbach D, Crawford YM, Braznin MB. Direct analysis of CYP21B genes in 21-hydroxylase deficiency using polymerase chain reaction amplification. Mol Endocrinol 1990; 4:125-31.

21 Wedell A, Ritzen EM, Haglund-Stengler B, Luthman $\mathrm{H}$ Steroid 21-hydroxylase deficiency: three additional mutated alleles and establishment of phenotype-genotype relationships of common mutations. Proc Natl Acad Sci USA 1992;89:7232-6.

22 Wedell A, Stengler B, Luthman H. Characterization of mutations on the rare duplicated C4/CYP21 haplotype in steroid 21-hydroxylase deficiency. Hum Genet 1994;94: $50-4$.

23 Tajima T, Fujieda K, Nakayama K, Fujii-Kuriyama Y. Molecular analysis of patient and carrier genes with congenital steroid 21-hydroxylase deficiency by using polymerase chain reaction and single strand conformation polymorphism. $\mathcal{f}$ Clin Invest 1993;92:2182-90.

24 Haliassos A, Chomel JC, Tesson L, et al. Modification of enzymatically amplified DNA for the detection of point mutations. Nucleic Acids Res 1989;17:3606.

25 Eiken HG, Odland E, Boman H, et al. Application of natural and amplification created restriction sites for the diagnosis and amplification created restriction sites for the diagnosis

26 Chang JG, Chen PH, Chiou SS, et al. Rapid diagnosis of $\beta$-thalassemia mutations in Chinese by naturally and amplified created restriction sites. Blood 1992;80:2092-6.

27 Nakahori Y, Takenaka O, Nakagome Y. A human X-Y homologous region encodes "Amelogenin". Genomics 1991;9:264-9. 